\title{
Cost of illness of the Cervical Cancer of the uterus in Japan - a time trend and future projections
}

\author{
Eijiro Hayata ${ }^{1}$, Kanako Seto ${ }^{2}$, Kayoko Haga ${ }^{2}$, Takefumi Kitazawa ${ }^{2}$, Kunichika Matsumoto ${ }^{2}$, Mineto Morita ${ }^{1}$ \\ and Tomonori Hasegawa ${ }^{2 *}$
}

\begin{abstract}
Background: Cervical cancer is associated with high morbidity and mortality rates among young women in Japan. The objective of this study was to assess and project the economic burden associated with cervical cancer in Japan and identify factors affecting future changes in this burden on society.

Methods: Utilizing government-based statistical nationwide data, we used the cost of illness (COI) method to estimate the COls for 1996, 1999, 2002, 2005, 2008, and 2011 to make predictions for 2014, 2017, and 2020. The COI comprised direct and indirect costs (morbidity and mortality costs).

Results: The COI was estimated to have increased by 66\% from 96.1 billion yen in 1996 to 159.9 billion yen in 2011 . The number of deaths increased, but the proportion of those aged $\geq 65$ years as a percentage of all deaths remained mostly unchanged, with no increase in the average age at death. The mortality cost per person was estimated to have increased (31.5 million yen in 1996 vs. 43.5 million yen in 2011). Assuming that the current trend in health-related indicators continues, the COI is predicted to temporarily decrease in 2014, followed by almost no change in 2020 (the estimated COI is 145.3-164.6 billion yen). The mortality cost per person is predicted to remain almost unchanged (39.4-46.3 million yen in 2020).

Conclusions: The fact that the life expectancy of affected individuals is not being prolonged and that the mortality in young individuals with a high human capital value is not decreasing may contribute to future sustainment of the COI. We believe that the results of the present study are applicable to discussions of disease control priorities.
\end{abstract}

Keywords: Cost of illness (COI), Economic burden of disease, Cervical cancer, Health economics, Health policy

\section{Background}

Cervical cancer (ICD-10 code: C53) affected 9,794 Japanese women in 2008 and resulted in 2,737 deaths in 2011, making it the 9th most common type of cancer in terms of morbidity and the 13th most common cancer in terms of mortality in women in these years [1]. However, when limited to women aged $<40$ years, it is the second most common cancer following breast cancer in terms of morbidity and the third most common cancer following breast and stomach cancer in terms of mortality [1].

Because cervical cancer is associated with high morbidity and mortality rates among relatively young women, its economic burden is predicted to change as women's

\footnotetext{
* Correspondence: tommie@med.toho-u.ac.jp

${ }^{2}$ Department of Social Medicine, Toho University School of Medicine,

5-21-16 Omori-nishi, Ota-ku, Tokyo 143-8540, Japan

Full list of author information is available at the end of the article
}

participation in society increases. However, few studies have estimated the economic burden of cervical cancer; most reports have estimated only direct treatment costs and performed cost-effectiveness analyses of specified technologies [2-4]. No such long-term studies have been conducted, and none have made future predictions. The objectives of the present study were to assess the economic burden of cervical cancer over time, make future predictions based on these observations, and identify the factors that drive the social burden of cervical cancer.

\footnotetext{
Methods

Analysis method

We used the cost of illness (COI) method to examine the economic burden of cervical cancer. Governmentbased statistical data and the COI method proposed by
}

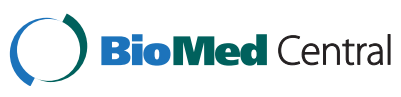

(c) 2015 Hayata et al.; licensee BioMed Central. This is an Open Access article distributed under the terms of the Creative Commons Attribution License (http://creativecommons.org/licenses/by/4.0), which permits unrestricted use, distribution, and reproduction in any medium, provided the original work is properly credited. The Creative Commons Public Domain Dedication waiver (http://creativecommons.org/publicdomain/zero/1.0/) applies to the data made available in this article, unless otherwise stated. 
Rice et al. were used to make COI estimates [5-12]. The COI includes both direct cost (DC) and indirect cost (IC); IC includes morbidity cost (MbC) and mortality cost $(\mathrm{MtC})$. The $\mathrm{COI}$ is calculated using following equation:

$$
\mathrm{COI}=\mathrm{DC}+\mathrm{MbC}+\mathrm{MtC}
$$

DCs are medical costs that arise directly as a result of disease, such as costs of treatment, hospitalization, testing, and drugs. We calculated the annual medical costs in the present study from the total medical expenses using the Survey of National Medical Care Insurance Services [13]. This survey only contains data for calculating DCs up to mid-level injuries and disease classifications such as uterine cancer (C53-55); it does not contain lower-level injury and disease classifications, such as cervical cancer of the uterus (C53). Therefore, we calculated DCs by proportionally distributing medical expenses based on the estimated number of patients (ENP) for cervical cancer (C53), endometrial cancer (C54), and other uterine cancers (C55) from the Patient Survey of the Ministry of Health, Labour and Welfare [14]. Thus, DC was calculated using the following equation:

$$
\mathrm{DC}=\mathrm{DC}(\mathrm{C} 53-55) \times \mathrm{C}(\mathrm{C} 5 \mathrm{C} 53) / \mathrm{ENP}(\mathrm{C} 53-55)
$$

ICs are opportunity costs lost as a result of disease or death. $\mathrm{MbC}$ and $\mathrm{MtC}$ were calculated using the following equations:

$$
\begin{aligned}
& \mathrm{MbC}=\mathrm{TOVy} \times \mathrm{OLVd} / 2+\mathrm{THD} \times / \mathrm{LVd} \text { and } \\
& \mathrm{MtC}=\mathrm{NDy} \times \mathrm{LVl},
\end{aligned}
$$

where TOVy is the total person-days of outpatient visits, LVd is the 1-day labor value per person, THD is the total person-days of hospitalization, NDy is the number of deaths, and $\mathrm{LVl}$ is the lifetime labor value per person.

The TOVy and THD according to 5-year age groups were calculated based on the above-mentioned Patient Survey [14]. The labor values were calculated according to 5-year age groups using the Basic Survey on Wage Structure [15], Labor Force Survey [16], Estimates of Monetary Valuation of Unpaid Work [17], and Evaluations of Domestic Labor [18], each of which is associated with a specific government office. The LVl was calculated by summing the income that could have been earned in the future if death had not occurred. We calculated the $\mathrm{MbC}$ by assuming a 1-day labor value loss for 1 hospitalized day and a half-day labor value loss for one outpatient visit. We used the number of deaths by cervical cancer according to 5-year age groups from the Vital Statistics of the Ministry of Health, Labour and Welfare [19].
LVd and THD were calculated as follows:

$$
\begin{aligned}
& \mathrm{LVd}=(\mathrm{Iy}+\mathrm{ULVy}) / 365 \text { and } \\
& \mathrm{THD}=\mathrm{HPy} \times \mathrm{ALOS},
\end{aligned}
$$

where Iy is the annual income per person [15], ULVy is the annual monetary valuation of unpaid work per person $[17,18]$, HPy is the annual number of hospitalized patients [14], and ALOS is the average length of stay [14]. The future labor value was adjusted to a present value using a $3 \%$ discount rate because $3 \%$ is widely used as discount rate in developed countries such as Japan and the United States, where application of the COI method is popular.

\section{COI estimates over time}

To examine changes over time, we first estimated the COIs for 1996, 1999, 2002, 2005, 2008, and 2011 using available data. The effect of introducing specific therapeutic techniques was not examined in this study.

Next, to make future predictions, we estimated the COIs for 2014, 2017, and 2020 using the two methods described below.

The first method involved fixing health-related indicators (mortality rate, average number of outpatient visits, average number of hospitalizations, average length of stay, and medical fees per examination) at the 2011 values and making estimates assuming changes in Japan's population and age composition (hereafter referred to as fixedmodel estimation). The data regarding medical fees per examination were obtained from the Patient Survey [14]. Using 2011 as the standard year, we first calculated the mortality rate, average number of outpatient visits, average number of hospitalizations, and average length of stay according to 5-year age groups in 2011. These data were multiplied by the estimated populations for 2014, 2017, and 2020 according to 5-year age groups to obtain the predicted mortality rate, average number of outpatient visits, average number of hospitalizations, and average length of stay for each year. Using data from 2011, the estimated average length of stay, mean life expectancy, and labor value were used to estimate $\mathrm{MbC}$ and $\mathrm{MtC}$. DCs were calculated by multiplying the rate of increase in outpatients and inpatients from 2011 to 2014, 2017, and 2020 by the outpatient and inpatient costs for 2011 .

The second method involved making estimates assuming continued trends in health-related indicators as well as changes in population and age compositions. After calculating approximation curves (logarithmic and linear approximations) for each item using data after 1996, we obtained figures for 2014, 2017, and 2020. We then calculated the annual rate of increase in medical fees per examination (outpatient and inpatient) [14] from 1996 to 2011 and corrected this increase by multiplying it by 
outpatient and inpatient costs for 2014, 2017, and 2020. When making future predictions using this method, estimates varied depending on which approximation with which they were calculated. Three patterns of estimates were made: estimates made from logarithmic approximations of all items (logarithm-model estimation), estimates made from linear approximations of all items (linear-model estimation), and estimates made from approximations of items with higher determination coefficients (mixed-model estimation). Logarithmic and linear estimates would produce different annual trends depending on the item; thus, single estimates are likely to produce overestimated or underestimated values. We therefore compared determination coefficients within the same age group in both the logarithmic and linear approximation curves and performed a mixed estimate using the curve with the higher coefficient in each age group. Mixedmodel estimation was considered the most likely estimates in this study. The elements used for calculation of the predicted future COI are shown in Table 1.

Table 1 Elements used for calculation of predicted future cost of illness

\begin{tabular}{|c|c|c|c|}
\hline Model & Item & Elements used for calculation & Fixed or Varied \\
\hline \multirow[t]{15}{*}{ Fixed model } & \multirow[t]{2}{*}{ Number of deaths } & Mortality rate & Fixed \\
\hline & & The population estimates & Varied \\
\hline & \multirow[t]{4}{*}{ Direct cost } & The expenses of outpatient visit and hospitalization & Fixed (Calculated using the unit cost in 2011) \\
\hline & & Medical fees per examination & Fixed \\
\hline & & Total person-days of outpatient visit & Varied \\
\hline & & Total person-days of hospitalizations & Varied \\
\hline & \multirow[t]{5}{*}{ Morbidity cost } & Average number of outpatients & Fixed \\
\hline & & Average number of hospitalizations & Fixed \\
\hline & & Average length of stay & Fixed \\
\hline & & The population estimates & varied \\
\hline & & Labor-value & Fixed \\
\hline & \multirow[t]{4}{*}{ Mortality cost } & Number of deaths & Varied \\
\hline & & Life expectancy & Fixed \\
\hline & & Labor-value & Fixed \\
\hline & & Discount rate: $3 \%$ & Fixed \\
\hline - Logarithm model & \multirow[t]{2}{*}{ Number of deaths } & Mortality rate & Varied (Calculated using the trend line formula) \\
\hline - Linear model & & The population estimates & Varied \\
\hline \multirow[t]{16}{*}{ - Mixed model } & \multirow[t]{4}{*}{ Direct cost } & The expenses of outpatient visit and hospitalization & Fixed (Calculated using the unit cost in 2011) \\
\hline & & Medical fees per examination & Varied \\
\hline & & Total person-days of outpatient visit & Varied \\
\hline & & Total person-days of hospitalization & Varied \\
\hline & \multirow[t]{8}{*}{ Morbidity cost } & Average number of outpatient visits & Varied (Calculated using the trend line formula) \\
\hline & & & (minimum value: the previous value before 0 ) \\
\hline & & Average number of hospitalizations & Varied (Calculated using the trend line formula) \\
\hline & & & (minimum value: the previous value before 0 ) \\
\hline & & Average length of stay & Varied (Calculated using the trend line formula) \\
\hline & & & (minimum value: 7.8 days) \\
\hline & & The population estimates & Varied \\
\hline & & Labor-value & Fixed \\
\hline & \multirow[t]{4}{*}{ Mortality cost } & Number of deaths & Varied \\
\hline & & Life expectancy & Fixed \\
\hline & & Labor-value & Fixed \\
\hline & & Discount rate: $3 \%$ & Fixed \\
\hline
\end{tabular}

Fixed: The value for 2011 was used. Varied: The values for 2014, 2017, and 2020 were calculated based on the trend line. 
Data from 2011 were used to determine the average life expectancy and the labor value. Additionally, the Population Estimates [20] by the Ministry of Internal Affairs and Communications were used for 1996, 2002, 2005, 2008, and 2011 population statistics, while the Population Projections for Japan [21] by the National Institute of Population and Social Security Research were used to make estimates for 2014, 2017, and 2020.

For estimates using approximation curves, some future predicted values may be $<0$; however, these are unlikely to reflect actual clinical conditions. Therefore, we defined "minimum values" in the present study as described below. For mortality and the numbers of outpatients and inpatients per person, the minimum value was set as the value from the year prior to that in which the estimate was $<0$. When examined according to age groups, we assumed that the value from the year prior to that when the estimate was $<0$ would be maintained thereafter and thus applied this value when estimates for 2014, 2017, and 2020 fell to $<0$. The minimum value for the average length of stay was set at 7.8 days, which is the average in 28 countries (2010) reporting data on neoplasms; this was based on the average length of stay by diagnostic categories in the OECD Health Data 2013 (statistics and indicators). According to the 2011 Patient Survey [14], the average length of stay for cervical cancer (17.8 days) did not differ greatly from the overall mean hospitalization period for malignant neoplasms (20.6 days); thus, we set the mean value for neoplasms in this study as the minimum length of stay for cervical cancer and applied this to age groups with hospitalization periods of $<7.8$ days in the estimates for 2014, 2017, and 2020. This study used only aggregated and published nationwide data that are freely available online; no humans or animals were used. In Japan, no institutional review board approval is required for this type of study [22].

\section{Results}

COI estimates for 1996, 1999, 2002, 2005, 2008, and 2011

The COI was estimated at 96.1 billion yen in 1996, 110.6 billion yen in 1999, 131.7 billion yen in 2002 , 133.4 billion yen in 2005, 145.5 billion yen in 2008, and 159.9 billion yen in 2011, indicating an increasing trend. Comparison of estimates from 1996 and 2011 revealed that the COI had increased by $66 \%$. The number of deaths increased, but the proportion of those aged $\geq 65$ years as a percentage of all deaths remained unchanged, with no increase in the average age at death. No change was observed in the fatality rate. The MtC per person calculated by dividing the MtC by the number of deaths followed an increasing trend (Table 2). Additional details of results (TOVy, THD, and $\mathrm{LVl}$ ) are provided in Additional file 1.

\section{COI estimates for 2014, 2017, and 2020}

\section{(fixed-model estimation)}

The COI was estimated at 159.5 billion yen for 2014, 158.9 billion yen for 2017, and 156.8 billion yen for 2020, with almost no change. $\mathrm{DC}, \mathrm{MbC}$, and $\mathrm{MtC}$ were

Table 2 Time trend of cost of illness of cervical cancer

\begin{tabular}{|c|c|c|c|c|c|c|}
\hline & 1996 & 1999 & 2002 & 2005 & 2008 & 2011 \\
\hline Population (thousand person) & 125,864 & 126,686 & 127,435 & 127,768 & 127,692 & 127,799 \\
\hline [\% of 65 years or older] & $15.1 \%$ & $16.7 \%$ & $18.5 \%$ & $20.2 \%$ & $22.1 \%$ & $23.1 \%$ \\
\hline Number of cervical cancer deaths (person) & 2,219 & 2,260 & 2,443 & 2,465 & 2,486 & 2,737 \\
\hline [\% of 65 years or older] & $51.7 \%$ & $51.1 \%$ & $47.7 \%$ & $48.2 \%$ & $47.7 \%$ & $49.6 \%$ \\
\hline Average age of death (year) & 64.1 & 63.6 & 62.9 & 63.6 & 63.4 & 64.0 \\
\hline Crude incidence rate (per 100 thousand, female) & 12.1 & 10.7 & 13.5 & 13.0 & 15.0 & NA \\
\hline Crude mortality rate (per 100 thousand, female) & 3.49 & 3.53 & 3.79 & 3.82 & 3.85 & 4.23 \\
\hline Fatality rate (female) & 0.29 & 0.33 & 0.28 & 0.29 & 0.26 & NA \\
\hline Direct cost (billion yen) & 15.8 & 26.0 & 20.1 & 25.3 & 33.6 & 31.0 \\
\hline Morbidity cost (billion yen) & 10.4 & 10.1 & 12.8 & 10.3 & 10.6 & 9.9 \\
\hline Mortality cost (billion yen) & 69.9 & 74.5 & 98.8 & 97.8 & 101.3 & 119.0 \\
\hline [\% of 65 years or older] & $16.6 \%$ & $15.4 \%$ & $15.8 \%$ & $16.9 \%$ & $15.2 \%$ & $17.5 \%$ \\
\hline Mortality cost per person (million yen) & 31.5 & 33.0 & 40.4 & 39.7 & 40.7 & 43.5 \\
\hline COI (billion yen) & 96.1 & 110.6 & 131.7 & 133.4 & 145.5 & 159.9 \\
\hline
\end{tabular}

Source of population: Ministry of Internal Affairs and Communications, Population Estimates.

Source of number of cervical cancer deaths: Vital Statistics.

Average age of death: Calculated according to the number of deaths, age (5-year age grades), and cause of death in Vital Statistics.

Source of crude morbidity rate and crude mortality rate: Center for Cancer Control and Information Services, National Cancer Center, Japan.

Fatality rate: Calculated by dividing the crude mortality rate by the crude morbidity rate.

NA: not available. 
all predicted to remain the same (Table 3). The predicted number of deaths showed an increasing trend and is expected to increase by $7.9 \%$ from 2011 to 2020. The proportion of deaths in individuals aged $\geq 65$ years is expected to increase ( $49.6 \%$ in $2011,56.8 \%$ in 2020 ), as is the average age at death (64.0 years in 2011, 66.3 years in 2020). The MtC of those aged $\geq 65$ years as a percentage of the total is expected to be $20.8 \%$ in 2020, showing a decreasing trend in the MtC per person.

Table 3 Future prediction of cost of illness

\begin{tabular}{|c|c|c|c|c|c|}
\hline Model & Item & 2011 & 2014 & 2017 & 2020 \\
\hline & Estimated population (thousand person) & 127,799 & 126,949 & 125,739 & 124,223 \\
\hline & [\% of 65 years or older] & $23.1 \%$ & $26.1 \%$ & $28.0 \%$ & $29.1 \%$ \\
\hline \multirow[t]{9}{*}{ Fixed model } & Number of cervical cancer deaths (person) & 2,737 & 2,816 & 2,900 & 2,953 \\
\hline & [\% of 65 years or older] & $49.6 \%$ & $53.0 \%$ & $55.5 \%$ & $56.8 \%$ \\
\hline & Average age of death (year) & 64.0 & 64.8 & 65.6 & 66.3 \\
\hline & Direct cost (billion yen) & 31.0 & 31.1 & 31.0 & 30.8 \\
\hline & Morbidity cost (billion yen) & 9.9 & 9.9 & 9.8 & 9.7 \\
\hline & Mortality cost (billion yen) & 119.0 & 118.5 & 118.1 & 116.3 \\
\hline & [\% of 65 years or older] & $17.5 \%$ & $19.3 \%$ & $20.5 \%$ & $20.8 \%$ \\
\hline & Mortality cost per person (million yen) & 43.5 & 42.1 & 40.7 & 39.4 \\
\hline & COI (billion yen) & 159.9 & 159.5 & 158.9 & 156.8 \\
\hline \multirow[t]{9}{*}{ Linear model } & Number of cervical cancer deaths (person) & 2,737 & 2,611 & 2,598 & 2,553 \\
\hline & [\% of 65 years or older] & $49.6 \%$ & $48.3 \%$ & $47.4 \%$ & $45.0 \%$ \\
\hline & Average age of death (year) & 64.0 & 63.1 & 62.8 & 62.3 \\
\hline & Direct cost (billion yen) & 31.0 & 23.1 & 20.8 & 22.2 \\
\hline & Morbidity cost (billion yen) & 9.9 & 6.7 & 5.5 & 5.0 \\
\hline & Mortality cost (billion yen) & 119.0 & 116.1 & 117.7 & 118.1 \\
\hline & [\% of 65 years or older] & $17.5 \%$ & $16.4 \%$ & $15.5 \%$ & $13.9 \%$ \\
\hline & Mortality cost per person (million yen) & 43.5 & 44.5 & 45.3 & 46.3 \\
\hline & COI (billion yen) & 159.9 & 145.9 & 144.0 & 145.3 \\
\hline \multirow[t]{9}{*}{ Logarithm model } & Number of cervical cancer deaths (person) & 2,737 & 2,714 & 2,772 & 2,812 \\
\hline & [\% of 65 years or older] & $49.6 \%$ & $52.6 \%$ & $54.0 \%$ & $54.6 \%$ \\
\hline & Average age of death (year) & 64.0 & 64.4 & 64.8 & 65.3 \\
\hline & Direct cost (billion yen) & 31.0 & 36.9 & 40.5 & 43.1 \\
\hline & Morbidity cost (billion yen) & 9.9 & 9.6 & 8.9 & 8.1 \\
\hline & Mortality cost (billion yen) & 119.0 & 113.3 & 114.0 & 113.4 \\
\hline & [\% of 65 years or older $]$ & $17.5 \%$ & $19.0 \%$ & $19.4 \%$ & $19.2 \%$ \\
\hline & Mortality cost per person (million yen) & 43.5 & 41.7 & 41.1 & 40.3 \\
\hline & COI (billion yen) & 159.9 & 159.8 & 163.4 & 164.6 \\
\hline \multirow[t]{9}{*}{ Mixed model } & Number of cervical cancer deaths (person) & 2,737 & 2,604 & 2,584 & 2,549 \\
\hline & [\% of 65 years or older] & $49.6 \%$ & $49.7 \%$ & $49.3 \%$ & $48.0 \%$ \\
\hline & Average age of death (year) & 64.0 & 63.5 & 63.3 & 63.2 \\
\hline & Direct cost (billion yen) & 31.0 & 27.7 & 26.6 & 28.4 \\
\hline & Morbidity cost (billion yen) & 9.9 & 7.8 & 6.8 & 6.4 \\
\hline & Mortality cost (billion yen) & 119.0 & 113.3 & 113.5 & 113.0 \\
\hline & [\% of 65 years or older] & $17.5 \%$ & $17.5 \%$ & $17.0 \%$ & $16.0 \%$ \\
\hline & Mortality cost per person (million yen) & 43.5 & 43.5 & 43.9 & 44.3 \\
\hline & COI (billion yen) & 159.9 & 148.8 & 146.9 & 147.8 \\
\hline
\end{tabular}




\section{COI estimates for 2014, 2017, and 2020}

(linear-, logarithm-, and mixed-model estimations)

According to the linear-model estimation, the COI was predicted to temporarily decrease to 145.9 billion yen in 2014, after which it is predicted to remain mostly unchanged at 144.0 billion yen in 2017 and 145.3 billion yen in 2020. This implies a 9.1\% decrease from 2011 to 2020. According to the logarithm-model estimation, the COI is estimated to remain mostly unchanged at 159.8 billion yen in 2014, 163.4 billion yen in 2017 , and 164.6 billion yen in 2020 . The predicted number of deaths is predicted to decrease in the linear-model estimation and increase in the logarithm-model estimation (Table 3).

The linear-model estimation showed that $\mathrm{DC}, \mathrm{MbC}$, and MtC will decrease temporarily in 2014, after which they will remain mostly unchanged until 2020. The logarithm-model estimation predicts that DC will increase, whereas $\mathrm{MbC}$ and $\mathrm{MtC}$ will decrease.

According to the mixed-model estimation, the COI was estimated to temporarily decrease to 148.8 billion yen in 2014, after which it will remain mostly unchanged at 146.9 billion yen in 2017 and 147.8 billion yen in 2020 . The rate of decrease from 2011 to 2020 is estimated at $7.6 \%$. The number of deaths and the $\mathrm{MbC}$ are estimated to decrease over time from 2011, and $\mathrm{DC}, \mathrm{MtC}$, and the COI will temporarily decrease in 2014, after which they are estimated to remain mostly unchanged until 2020. Although mixed-model estimation is predicted to be below fixed-model estimation for all items, they are predicted to exceed linear estimates. The proportion of deaths in those aged $\geq 65$ years is expected to decrease to $48.0 \%$ in 2020 , and the average age at death will decrease to 63.2 years. Furthermore, the MtC per person is predicted to increase to 44.3 million yen, and the proportion of those aged $\geq 65$ years as a percentage of $\mathrm{MtC}$ is estimated to decrease to $16.0 \%$.

The COI over time from 1996 is shown in Figures 1 and 2. The results suggest that the COI of cervical cancer will temporarily decrease and then remain mostly unchanged.

\section{Discussion}

The COI increased from 1996 to 2011. Based on our future predictions, the COI is estimated to remain unchanged according to fixed-model estimates. However, assuming that current trends in health-related indicators continue, linear-model estimates show that the COI will temporarily decrease in 2014, followed by almost no change. On the other hand, logarithmic-model estimates suggest that the trends will remain mostly unchanged from 2011. Mixed-model estimates, which are considered the most reliable, show that despite the decreased number of deaths, the COI will remain mostly

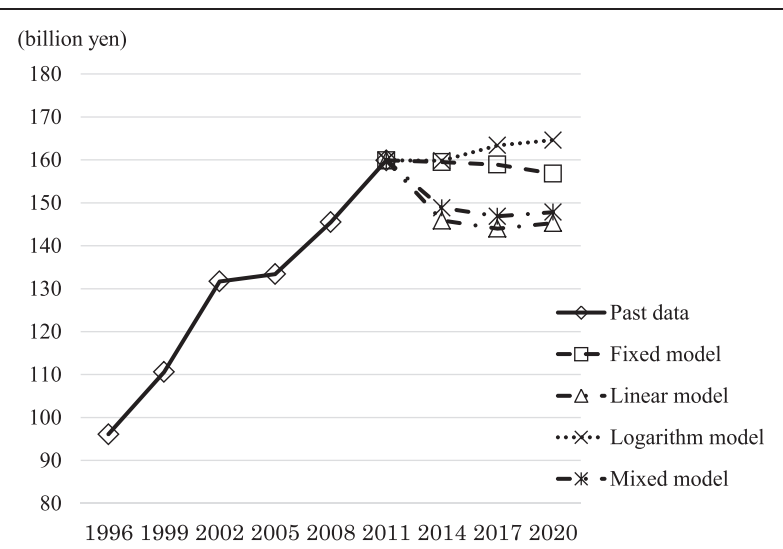

Figure 1 Time trends of cost of illness by prediction models.

unchanged from 2014, with DC and MtC following the same trend. The main model used in our analysis was the mixed model. The fixed model was a reference. The linear and logarithm models provide low-end and high-end estimation, respectively, and they can be regarded as sensitivity analyses that show the robustness of the mixed model.

Factors that influenced the increase in the COI from 1996 to 2011 were greater DC and MtC. In contrast, $\mathrm{MbC}$ remained mostly unchanged. The medical fees per examination of patients with uterine cancer increased by $5.3 \%$ annually, which is believed to be linked to greater $\mathrm{DC}$ due to the increasing trend in the estimated number of patients. The increase in medical fees per examination is likely influenced by recent advancements in medical care. On the other hand, the mean length of hospitalization has shown a consistent downward trend, which may explain the lack of the increase in $\mathrm{MbC}$, canceling out the increase in medical fees and opportunity costs lost as a result of hospitalization. The increase in $\mathrm{MtC}$ is important considering the age at death of patients with cervical cancer and the impact of aging in Japan. The average age at death has remained mostly unchanged due to a twin-peak pattern of increasing numbers of deaths at younger ages (30-64 years) and older ages ( $\geq 75$ years) [19]. In general, because the fatality rate in the older population is high, aging is a factor that increases the number of deaths and MtC. However, aging also decreases $\mathrm{MtC}$ because older individuals have relatively lower human capital value. Thus, the impact of aging on $\mathrm{MtC}$ is relatively small. However, increased numbers of deaths of young people contributes significantly to the increase in $\mathrm{MtC}$. The annual labor value per person is increasing due to the increase in the labor force participation rate among young women and increasing annual incomes, which reflect the social advancement of women. The increase in the number of deaths and labor value per person among young women is believed to be a significant factor affecting the increase in $\mathrm{MtC}$ (Table 4). In a previous report [23] in 


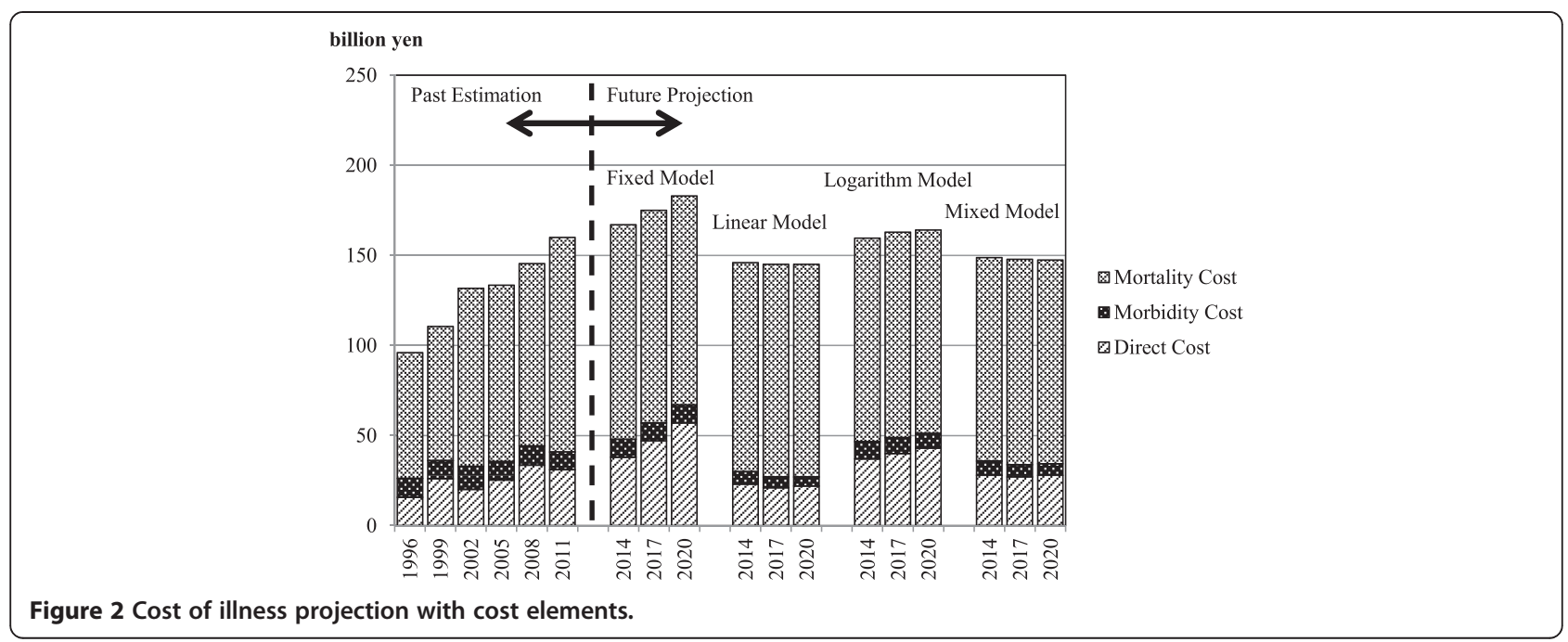

which the $\mathrm{COI}$ of stomach cancer was estimated using the same method described herein, the COI of stomach cancer decreased by $13.9 \%$ from 1996 to 2008, which can be attributed to decreased $\mathrm{MbC}$ and $\mathrm{MtC}$. Although the number of stomach cancer-related deaths remained unchanged, the average age at death increased, which may have led to a decrease in the MtC per person and an overall decrease in $\mathrm{MtC}$. Additionally, the decreased number of outpatients and inpatients and shortened hospitalization may have reduced $\mathrm{MbC}$. The present study shows a COI trend opposite to that in the above-mentioned study. COI trends differ according to patient attributes and disease features, even for the same solid cancer. Comparison of each factor influencing the COI would allow for evaluation of the characteristics of the economic burden of each disease, which would contribute to the design of future health policies.

According to our future predictions (fixed-model estimation), the number of deaths will increase, but the COI, $\mathrm{DC}, \mathrm{MbC}$, and $\mathrm{MtC}$ are estimated to remain unchanged. In particular, $\mathrm{MtC}$ is estimated to decrease to no more than $2.3 \%$ irrespective of the fact that the number of deaths will increase by $7.8 \%$ from 2011 to 2020 . The increase in the proportion of deaths in those aged $\geq 65$ years (49.6\% in 2011, 56.8\% in 2020), the increase in the average age at death (64.0 in 2011, 66.3 in 2020), and the decrease in the $\mathrm{MtC}$ per person as a result of the reduced human capital value (43.5 million yen in 2011, 39.4 million yen in 2020) are estimated to be offset by the pressure of increased $\mathrm{MtC}$ from the increased number of deaths.

Table 4 Time trend of number of cervical cancer deaths, labor force participation rate, annual income, and annual labor value

\begin{tabular}{|c|c|c|c|c|c|c|c|c|c|c|c|c|c|c|}
\hline & & $25-29$ & $30-34$ & $35-39$ & $40-44$ & $45-49$ & $50-54$ & 55-59 & $60-64$ & $65-69$ & $70-74$ & $75-79$ & $80-84$ & 85- \\
\hline \multirow{3}{*}{$\begin{array}{l}\text { Number of cervical } \\
\text { cancer deaths } \\
\text { (person) [19] }\end{array}$} & 1996 & 16 & 44 & 68 & 105 & 209 & 195 & 210 & 224 & 256 & 233 & 251 & 208 & 200 \\
\hline & 2011 & 19 & 68 & 118 & 202 & 219 & 221 & 228 & 304 & 231 & 220 & 281 & 270 & 356 \\
\hline & changing rate & $18.8 \%$ & $54.5 \%$ & $73.5 \%$ & $92.4 \%$ & $4.8 \%$ & $13.3 \%$ & $8.6 \%$ & $35.7 \%$ & $-9.8 \%$ & $-5.6 \%$ & $12.0 \%$ & $29.8 \%$ & $78.0 \%$ \\
\hline \multirow{3}{*}{$\begin{array}{l}\text { Labor force } \\
\text { participation rate } \\
\text { (\%) [16] }\end{array}$} & 1996 & 67.9 & 54.8 & 60.8 & 69.5 & 71.6 & 66.9 & 58.1 & 39.0 & 27.0 & 10.1 & 0 & 0 & 0 \\
\hline & 2011 & 77.0 & 67.5 & 67.0 & 71.2 & 75.7 & 72.6 & 64.0 & 45.7 & 27.6 & 8.6 & 0 & 0 & 0 \\
\hline & changing rate & $13.4 \%$ & $23.2 \%$ & $10.2 \%$ & $2.4 \%$ & $5.7 \%$ & $8.5 \%$ & $10.2 \%$ & $17.2 \%$ & $2.2 \%$ & $-14.9 \%$ & $0.0 \%$ & $0.0 \%$ & $0.0 \%$ \\
\hline \multirow{3}{*}{$\begin{array}{l}\text { Annual income } \\
\text { per person } \\
\text { (thousand yen) [15] }\end{array}$} & 1996 & 1817 & 1578 & 1802 & 2010 & 2036 & 1887 & 1555 & 969 & 664 & 248 & 0 & 0 & 0 \\
\hline & 2011 & 2176 & 2050 & 2132 & 2321 & 2457 & 2323 & 1942 & 1173 & 678 & 230 & 0 & 0 & 0 \\
\hline & changing rate & $19.8 \%$ & $29.9 \%$ & $18.3 \%$ & $15.5 \%$ & $20.7 \%$ & $23.1 \%$ & $24.9 \%$ & $21.1 \%$ & $2.1 \%$ & $-7.3 \%$ & $0.0 \%$ & $0.0 \%$ & $0.0 \%$ \\
\hline \multirow{3}{*}{$\begin{array}{l}\text { Annual labor value } \\
\text { per person } \\
\text { (thousand yen) }\end{array}$} & 1996 & 3584 & 4064 & 4288 & 4051 & 4078 & 3745 & 3414 & 2837 & 2297 & 1684 & 1181 & 742 & 304 \\
\hline & 2011 & 3493 & 4339 & 4900 & 5087 & 5004 & 4681 & 4305 & 3223 & 2608 & 2301 & 1837 & 1513 & 800 \\
\hline & changing rate & $-2.5 \%$ & $6.8 \%$ & $14.3 \%$ & $25.6 \%$ & $22.7 \%$ & $25.0 \%$ & $26.1 \%$ & $13.6 \%$ & $13.5 \%$ & $36.6 \%$ & $55.5 \%$ & $103.9 \%$ & $163.2 \%$ \\
\hline
\end{tabular}

Source of number of cervical cancer deaths: Vital Statistics [19].

Source of labor force participation rate: Labor Force Survey, Ministry of Internal Affairs and Communications [16].

Source of annual income per person: Basic Survey on Wage Structure, Ministry of Health, Labour and Welfare [15].

Annual labor value per person: Calculated according to annual income per person, labor force participation rate, and estimates of monetary valuation of unpaid work. 
According to the mixed-model estimation, the COI is estimated to temporarily decrease in 2014 , followed by almost no change thereafter. The same trend is expected for the number of deaths, $\mathrm{DC}, \mathrm{MbC}$, and MtC. The proportion of deaths in those aged $\geq 65$ years will decrease (49.6\% in 2011, 48.0\% in 2020), as will the average age at death (64.0 in 2011, 63.2 in 2020), and the MtC per person will increase (43.5 million yen in 2011, 44.3 million yen in 2020). The previously mentioned COI estimates of stomach cancer [22] predict decreases in the number of deaths, $\mathrm{DC}, \mathrm{MbC}, \mathrm{MtC}$, and overall COI. In particular, a $25.1 \%$ decrease in the number of deaths and a $55.6 \%$ decrease in MtC from 2008 to 2020 are likely factors influencing these estimates. The increase in the average age at death and the sharp decline in the number of deaths among young people with a high human capital value are predicted to be linked to decreased MtC. Compared with stomach cancer, no increase in the average age at death can be observed for cervical cancer, and the lack of the reduction in the number of deaths among young women with high human capital value is a likely factor preventing future reductions in the COI. COI may rather increase in the future because of the promotion of women's participation in society and the increase in the human capital value of young people. This finding suggests that interventions for younger women can be an important political challenge. Several studies on the economic burden of cervical cancer have been conducted in other countries. For example, Ricciardi et al. [24] estimated the annual DC of managing invasive cancer in Italy as 28.3 million Euro per year. In 2003, Olivia et al. [25] estimated the IC of cervical cancer in Spain using two alternative approaches (human capital method and friction cost method). The annual IC was estimated as 43.4 million Euro by the human capital method and 1.1 million Euro by the friction cost method. However, no such long-term studies have been conducted, and none have made future predictions. Therefore, this is one of the advantages of our study.

Routine prophylactic vaccination against cervical cancer is currently being introduced in Japan. Prophylactic vaccination against cervical cancer is expected to further reduce the number of patients with cervical cancer and related deaths, which should contribute to reducing the COI.

A limitation of the present study is the fact that the COI method only analyzes macroestimates of costs without taking into account the quality of medical care or quality of life, and it does not involve verification of the cost effectiveness of microlevel therapeutic techniques. Moreover, to who and what these costs apply is unclear. For example, several studies have reported the economic effects of prophylactic vaccination against human papillomavirus [3,26-28], and prophylactic vaccination may help to reduce the healthcare costs associated with cervical cancer. Our study does not take the effect of a specific treatment technology into consideration; a further study of COI that includes the possible effect of prophylactic vaccination against cervical cancer treatment would be needed. In addition, because the annual labor value is fixed at the 2011 value, as women's participation in society continues to accelerate and their incomes increase, $\mathrm{MbC}$ and $\mathrm{MtC}$ are likely to be underestimated using this method. However, the COI method enables the support of rational decision-making through the efficient use of limited medical resources by measuring the monetary value of disease burden [6,7]. Furthermore, this method provides basic information on policy-making related to prevention and management activities for injuries and diseases that justify intervention plans [10]. Therefore, the knowledge obtained from the present study is valid and can be applied to future policy-making.

\section{Conclusions}

We made future predictions of the COI of cervical cancer using government statistics. According to our mixed estimates, which are considered highly valid, if the current trends in health-related indicators continue, the COI will temporarily decrease in 2014, followed by almost no change until 2020. The lack of a prolonged life expectancy in individuals with cervical cancer and the lack of a decrease in the number of deaths among young women with a high human capital value are likely factors preventing a future reduction in the COI. Interventions involving young women have high political priority because the COI has high possibility to increase in the future secondary to the promotion of women's participation in society.

\section{Additional file}

Additional file 1: Time trend of total person-days of outpatient visits (TOVy), total person-days of hospitalization (THD), and lifetime labor value per person (LVI).

\section{Abbreviations}

COI: Cost of illness; DC: Direct cost; IC: Indirect cost; MbC: Morbidity cost; MtC: Mortality cost; ENP: Estimated number of patients; LVd: 1-day labor value per person; LVI: Lifetime labor value per person; TOVy: Total person-days of outpatient visits; THD: Total person-days of hospitalization; NDy: Number of deaths; ly: Annual income per person; ULVy: Annual monetary valuation of unpaid work per person; HPy: Annual number of hospitalized patients; ALOS: Average length of stay.

\section{Competing interests}

The authors declare that they have no competing interests.

\section{Authors' contributions}

EH participated in the design of the study, performed the data collection and the analysis, and drafted the manuscript. KS and KM participated in the design of the study and performed the data analysis. $\mathrm{KH}$ and TK performed the data collection and analysis. MM and TH conceived of and helped to design the study and helped to draft the manuscript. All authors read and approved the final manuscript. 


\section{Acknowledgements}

There are no specific contributors to acknowledge. No funding agency or grant supported this project.

\section{Author details}

'Department of Obstetrics and Gynecology, Toho University Omori Medical Center, 6-11-1 Omori-nishi, Ota-ku, Tokyo 143-8541, Japan. ²Department of Social Medicine, Toho University School of Medicine, 5-21-16 Omori-nishi, Ota-ku, Tokyo 143-8540, Japan.

Received: 14 May 2014 Accepted: 2 March 2015

Published online: 15 March 2015

\section{References}

1. Center for Cancer Control and Information Services, National Cancer Center: Cancer Information Service Homepage. [http://ganjoho.jp/pro/statistics/ gdb_year.html?1\%1]

2. Uemura K, Kougo M, Okubo K, Okai T, Yoneyama K, Kiuchi Y. Cost-effectiveness analysis of initial treatment for cervical cancer patients. Clin Gynecol Obstet. 2008;62(2):209-16.

3. Konno R, Sasagawa T, Fukuda T, Georges VK, Nadia D. Cost-effectiveness analysis of prophylactic cervical cancer vaccination in Japanese women. Obstet Gynecolog Ther. 2008;97(5):530-42

4. Arakawa I, Kawabayashi Y, Furuno M, Uchida M, Kawana T. Economic evaluation for the prevention of cervical cancer by vaccination-from the perspective of health insurance society and industry. Jpn J Cancer Chemother. 2013;40(4):493-8.

5. Rice DP. Estimating the cost of illness. Am J Public Health Nations Health. 1967;57(3):424-40

6. Rice DP, Hodgson TA. The value of human life revisited. Am J Public Health. 1982;72:536-8

7. Crum GE, Rice DP, Hodgson TA. The priceless value of human life. Am J Public Health. 1982:72:1299-300

8. Rice DP, Hodgson TA, Kopstein AN. The economic costs of illness: a replication and update. Health Care Financ Rev. 1985;7:61-80.

9. Rice DP. Cost-of-illness studies: fact or fiction? Lancet. 1994;344:1519-20.

10. Rice DP. Cost of illness studies: what is good about them? Inj Prev. 2000;6:177-9.

11. Tarricone R. Cost-of-illness analysis: what room in health economics? Health Policy. 2006;77:51-63.

12. Hodgson TA, Meiners MR. Cost-of-illness methodology: a guide to current practices and procedures. Milbank Mem Fund Q Health Soc. 1982;60:429-62.

13. Survey of National Medical Care Insurance Services, Ministry of Health, Labour and Welfare. [http://www.mhlw.go.jp/toukei/list/26-19.html]

14. Patient survey, Ministry of Health, Labour and Welfare. [http://www.mhlw.go.jp/toukei/list/10-20.html]

15. Basic survey on wage structure, Ministry of Health, Labour and Welfare. [http://www.mhlw.go.jp/toukei/list/chingin_zenkoku.html]

16. Labor force survey, Ministry of Internal Affairs and Communications. [http://www.stat.go.jp/data/roudou/]

17. Cabinet Office: System of National Accounts, Satellite Accounts, and Unpaid Work. [http://www.esri.cao.go.jp/jp/sna/sonota/satellite/satellite_top.html]

18. Cabinet Office: System of National Accounts, Satellite Accounts, and Unpaid Work. [http://www.esri.cao.go.jp/jp/sna/sonota/satellite/roudou/contents/ 20090824g-unpaid.html]

19. Vital statistics, Ministry of Health, Labour and Welfare. [http://www.mhlw.go. jp/english/database/db-hw/vs01.html]

20. Population Estimates, Ministry of Internal Affairs and Communications. [http://www.stat.go.jp/data/jinsui/]

21. Population Projections for Japan, National Institute of Population and Social Security Research. [http://www.ipss.go.jp/syoushika/tohkei/suikei07/ suikei.html\#chapt1-1]

22. Ethical Guidelines for Epidemiological Research: [http://www.lifescience. mext.go.jp/files/pdf/n796_01.pdf(accessed on Apr. 15 2014)]

23. Haga K, Matsumoto K, Kitazawa T, Seto K, Fujita S, Hasegawa T. Cost of illness of the stomach cancer in Japan - a time trend and future projections. BMC Health Serv Res. 2013:13:283.

24. Ricciardi A, Larrgeon N, Giorgi Rossi P, Raffaele M, Chet C, Federici A, et al. Incidence of invasive cervical cancer and direct costs associated with its management in Italy. Tumori. 2009;95:146-52.
25. Olivia J, Lobo F, Lopez-Bastida J, Zozaya N, Romay R. Indirect costs of cervical and breast cancers in Spain. Eur J Health Econ. 2005:6:309-13.

26. Fleurence RL, Dixon JM, Milanova TF, Beusterien KM. Review of the economic and quality-of-life burden of cervical human papillomavirus disease. Am J Obstet Gynecol. 2003;196:206-12.

27. Prasad SR, Hill R. Cost-benefit analysis on the HPV vaccine in Medicaid-enrolled females of the Appalachian region of Kentucky. J Ky Med Assoc. 2008;106:271-6.

28. Chesson HW, Ekwueme DU, Saraiya M, Watson M, Lowy DR, Markowitz LE. Estimates of the annual direct medical costs of the prevention and treatment of disease associated with human papillomavirus in the United States. Vaccine. 2012;30:6016-9.

\section{Submit your next manuscript to BioMed Central and take full advantage of:}

- Convenient online submission

- Thorough peer review

- No space constraints or color figure charges

- Immediate publication on acceptance

- Inclusion in PubMed, CAS, Scopus and Google Scholar

- Research which is freely available for redistribution

Submit your manuscript at www.biomedcentral.com/submit 